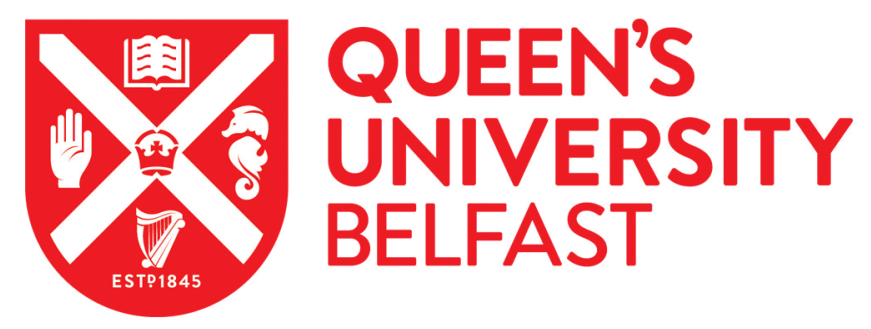

\title{
Fracture Critical Length Estimative Using Percolation Theory and Well Logging Data
}

\author{
Kowalski, A. C. G., Mendonça, C. A., Ofterdinger, U. S., \& Rocha, H. R. (2021). Fracture Critical Length \\ Estimative Using Percolation Theory and Well Logging Data. Journal of Environmental and Engineering \\ Geophysics, 26(4), 279-286. https://doi.org/10.32389/JEEG21-019
}

\section{Published in:}

Journal of Environmental and Engineering Geophysics

\section{Document Version:}

Publisher's PDF, also known as Version of record

\section{Queen's University Belfast - Research Portal:}

Link to publication record in Queen's University Belfast Research Portal

\section{Publisher rights}

Copyright 2021, The Environmental and Engineering Geophysical Society

This work is made available online in accordance with the publisher's policies. Please refer to any applicable terms of use of the publisher.

\section{General rights}

Copyright for the publications made accessible via the Queen's University Belfast Research Portal is retained by the author(s) and / or other copyright owners and it is a condition of accessing these publications that users recognise and abide by the legal requirements associated with these rights.

\section{Take down policy}

The Research Portal is Queen's institutional repository that provides access to Queen's research output. Every effort has been made to ensure that content in the Research Portal does not infringe any person's rights, or applicable UK laws. If you discover content in the Research Portal that you believe breaches copyright or violates any law, please contact openaccess@qub.ac.uk. 


\title{
Journal of Environmental and Engineering Geophysics
}

\section{Fracture Critical Length Estimative Using Percolation Theory and Well Logging Data}

\author{
André C.G. Kowalski ${ }^{1,}$, Carlos A. Mendonça ${ }^{1}$, Ulrich S. Ofterdinger ${ }^{2}$ and Humberto R. Rocha ${ }^{3}$ \\ ${ }^{1}$ Department of Geophysics, University of São Paulo, Rua do Matão, 1226, São Paulo 05508-090, Brazil \\ ${ }^{2}$ School of Natural and Built Environment, Queen's University Belfast, David Keir Building, Stranmillis Road, Northern Ireland BT9 \\ $5 A G$, UK \\ ${ }^{3}$ Department of Atmospheric Sciences, University of São Paulo, Rua do Matão, 1226, São Paulo 05508-090, Brazil
}

"Corresponding author email: andre.kowalski@iag.usp.br

\begin{abstract}
Groundwater transport in crystalline rocks follows pathways along fractured zones because of low primary porosity and permeability in such formations. Fractured systems encompass an imbricated set of joints and fractures with different lengths, apertures and orientations resulting in complex permeable systems with heterogeneous groundwater transport properties. Geophysical well logging has proved effectiveness in detecting depth levels with denser fracture distributions as well as the apparent aperture of fractures contributing to groundwater flow. In many cases, the extension spanned by a fracture network cannot be directly inferred because it may extend beyond the radius of investigation of common well logging probes, thus preventing quantitative estimation of critical length for lateral extension a connected fractured system may have. Here we apply a percolation theory model to estimate the critical length as inferred from the linear density of fracture distribution observed at the borehole wall with an optical imaging probe. Our results are analyzed with electrical well logging data (normal resistivity and single-point resistance) cross borehole slug tests using a set of three boreholes. A critical length of $3.9 \mathrm{~m}$ was inferred with a percolation model which revealed consistency with the cross borehole slug tests from two wells situated $10 \mathrm{~m}$ and $30 \mathrm{~m}$ in the vicinity of the monitored borehole. Our results suggest the utility of inferring critical percolation lengths from fracture parameters obtained using standard well logging imaging techniques with potential applications to evaluate groundwater resources, characterize contaminated sites and provide geotechnical information for works in fractured formations.
\end{abstract} ABSTRACT

\section{INTRODUCTION}

Crystalline igneous and metamorphic hard rocks are usually associated with low primary porosity and permeability such that water or contaminant movement in these natural geological formations is conditioned by the transmissivity and extension of connected fractured zones. Fluid flow regime in hard rock terrains is relevant in many hydrogeological investigations such as to evaluate groundwater well productivity for public supply (Boutt et al., 2010; Boisson et al., 2015), feasibility of underground nuclear waste repositories (Karasaki et al., 2000), water inflow into tunnel constructions (Stumm et al., 2007) and other subsurface mining or civil engineering projects. Borehole geophysics are commonly used in fractured rock investigations because well logging techniques allow measuring different physical properties along the well (fluid temperature and electrical conductivity, natural gamma ray radiation, electrical resistivity, single-point resistance, acoustic wave travel speed, etc.) that are useful to characterize properties of geological formations intercepted by the well (Keys, 1990).

One commonly used logging technique is the direct imaging of the borehole wall with optical or acoustical probes allowing a quantitative fracture analysis as it is done in structural geology with outcrops. Borehole wall imaging can distinguish active and sealed fractures (Shapiro, 2001), evaluate the fracture transmissivity when integrated with adequate pumping tests (Hamm et al., 2007) or hydraulic head estimates from monitoring electrokinetic signals after pumping a well (Kowalski et al., 2021). Image logs also allow predetermination of depths of interest for selective measurements with flowmeter probes (Williams and Paillet, 2002) to detect potential fractures as a nearby well is pumped (Vitale et al., 2019). In addition to pumping tests, dilution tests (Collins and Bianchi, 2020) and cross borehole slug tests (Audouin and Bodin, 2008) can be monitored to identify connected systems. Most procedures inferring fracture extension and connectivity length are based on well-testing, thus requiring a set of well-distributed boreholes and expensive field work. 


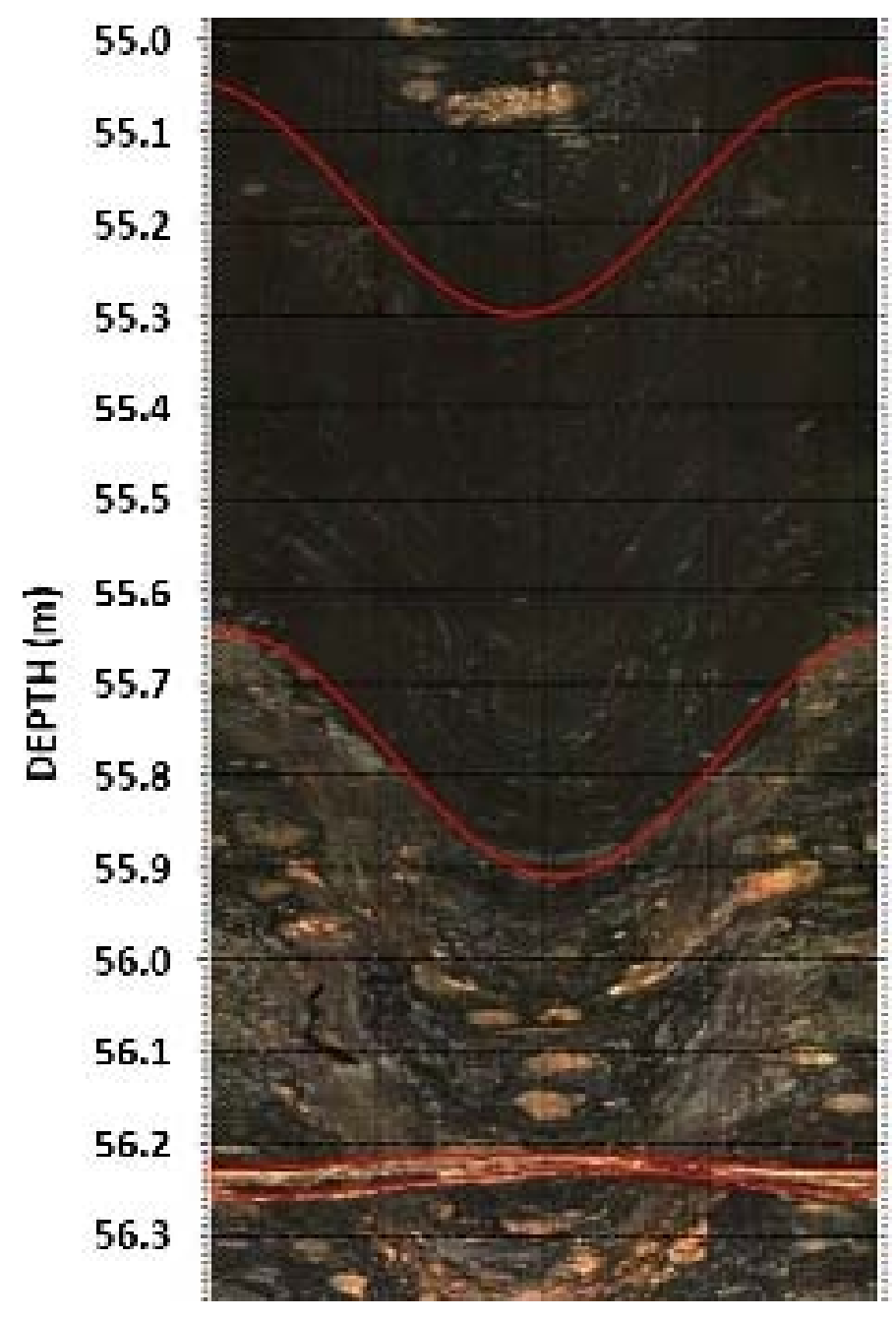

Figure 1 Example of image from a borehole sitting in crystalline rock obtained using an optical televiewer probe. Depth interval between 55.0 to $56.3 \mathrm{~m}$ where red traces are interpretations of structures intercepted by the borehole which allow to determine the depth, orientation, inclination and visual aperture of fractures, as well as the linear fracture density.

We present a field study using optical and electrical well logging techniques to evaluate what is termed as percolation threshold for a fractured medium by using as input the linear density of fractures, a parameter that common imaging probes for borehole walls may provide (Fig. 1). For this evaluation we used a statistical model proposed by Bour and Davy (1997) which is based on the percolation theory (Broadbent and Hammersley, 1957). The concept of percolation threshold stands for the minimum length an element of a physical system must have to develop a connected pathway across the medium. For fractured systems, this can be associated with length of fractures allowing a continuous flow line across rock mass (Berkowitz, 1995; Berkowitz, 2002). Statistical analysis of the percolation threshold has been applied to characterize fractured basalt layers in the oceanic crust (Zimmermann et al.,
2005 ) but, to our knowledge, not applied in rock mass evaluation for geotechnical or groundwater studies.

In the following sections, we present basic information about the percolation theory as applied to groundwater problems, to then describe a field test in which the percolation threshold is estimated from conventional well logging techniques and analyzed by cross borehole slug testing while monitoring water head variations in all three boreholes.

\section{Percolation Threshold}

The percolation theory was introduced by Broadbent and Hammersley (1957) when comparing percolation processes with diffusion phenomena. Since then, percolation theory has been applied to study a variety of media presenting low transport properties with transmissivities conditioned by random distributions in its conductive elements (Stauffer and Aharony, 1992) with many applications in petrophysical models (Gueguen and Dienes, 1989; Balberg et al., 1991; Ozkaya and Mattner, 2003). As shown in Fig. 2, the principles of the percolation theory can be illustrated by considering a two-dimensional matrix where each element can be randomly occupied with probability $p$ or empty with $1-p$, where $p=1$ means that every element of the matrix is occupied. In such representation, there is a limit for probability $p$ after which occupied elements of the matrix are connected and develop a continuous path across media. A connected pathway is commonly referred to as "backbone" and defines a characteristic length for the underlying transport phenomena. Bellow this critical limit, known as "percolation threshold" or probability $p_{C}$, the chance of a fracture belonging to the backbone is null (Bunde and Kantelhardt, 2005). This means that only above this characteristic limit a transport process can be regarded as feasible in such a medium (no connected pathway below this limit) which in the field of hydraulics is related to the concept of effective porosity.

A formulation to apply percolation theory to characterize fractured systems in hydrological studies was developed by Bour and Davy (1997). Their formulation represents a fractured rock mass as a two-dimensional network with discrete fractures of same length $l$ randomly distributed in terms of orientation. The critical probability associated to this idealized fractured system can be determined as

$$
\rho_{c}=\frac{N l^{2}}{A}=\lambda_{A} l^{2}
$$

where $N$ is the total number of fractures, and $A$ is the area spanned by the fracture network. Parameter $\lambda_{A}=$ $N / A$ then expresses the surface density for the fractures. A correspondent linear density of fractures 

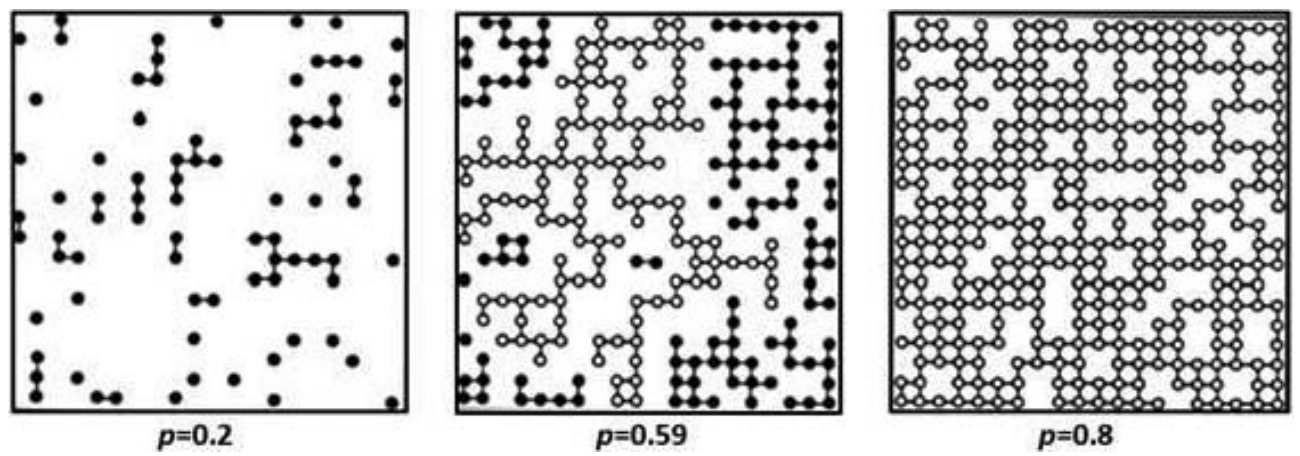

Figure 2 Representation of percolation limits in a medium where each element has a probability $(p)$ of being occupied by a fracture or empty $(1-$ $p$ ). Black circles indicate fractures isolated or connected to small networks, and white circles indicate fractures connected to a network of flow through the whole media. From left to right, as probability $p$ increases, chances of developing a connected fracture network also increases. When the percolation threshold is reached at $p_{C}=0.59$, fractures develop a connected pathway which spans the whole system allowing flow between its boundaries (Adapted from Bunde and Kantelhardt, 2005).

can be defined as $\lambda_{L}=n / z_{w}$, by assuming that $n$ fractures are observed along a straight line of length $z_{w}$, such as in a borehole. By assuming a power law fracture length distribution where $\mu_{L}$ is the mean length, the surface and linear fracture densities are coupled (Zimmermann et al., 2005) as

$$
\frac{2}{\pi} \lambda_{A} \mu_{L} \leq \lambda_{L} \leq \lambda_{A} \mu_{L}
$$

The lower limit in this relationship accounts for a fractured system with fractures randomly distributed in terms of directions, meanwhile the upper limit represents a distribution with coplanar fractures. According to relationships 1 and 2, the lower boundary for the percolation threshold is

$$
\rho_{c}=\frac{2}{\pi} \lambda_{A} \mu_{L} \geq \lambda_{L} \mu_{L}
$$

as such associated to a measurable parameter one can obtain from exposed bed rocks or in boreholes. By assuming a system with randomly distributed fractures, the percolation parameter $p_{c}$ can be analytically determined as equal to 5.6 (Bour and Davy, 1997). Considering then $l_{c} \approx \mu_{L}$ the critical length then can be determined as a function of $\lambda_{L}$ as

$$
l_{c}=\frac{5.6}{\lambda_{L}}
$$

Equation 4 is a nodal point justifying the application of borehole imaging to determine linear fracture density for inferences about critical length of percolation associated with the unknown medium under test. Determination of critical length $l_{c}$ provides means to estimate the radius of influence of the borehole, i.e., the distance from the borehole at which the water table isn't affected when the borehole is pumped, and is needed when calculating individual fracture transmissivity from well logging data (DayLewis et al., 2011; Barbosa et al., 2020).

\section{Well Logging Techniques}

This section describes well logging techniques we used to determine the percolation parameter from a field test, and auxiliary techniques to analyze our results. Well logging optical imaging of the borehole wall (OPTV-Optical Borehole Televiewer) allows identification of the main fractured zones as well as quantitative inferences about the apparent aperture and structural parameters (strike and dip angle) for specific fractures (Williams and Johnson, 2004). The term "apparent aperture" is usually employed to describe the visual aperture identified from an imaging probe of the borehole wall, which may differ from the effective hydraulic aperture.

The OPTV method uses a digital camera installed in a logging probe, with a light source to make complete imaging of the borehole wall. A triaxial magnetometer and a set of inclinometers provide the camera with a reference positioning frame, necessary to compute dip and azimuth for features in the borehole wall, used as input to the fracture traces recorded in the digital images. High-resolution optical imaging of the borehole wall requires empty or clean water filled boreholes, although in the latter case it is possible to use acoustical imaging logging (Williams and Johnson, 2004).

Measurements of electrical resistivity or singlepoint resistance can be used to characterize specific fractures or fractured zones as a function of the borehole depth. The resistivity logging method (Keys, 1990), usually acquired with the "normal resistivity" array in common groundwater probes, employs a pair of electrodes to inject direct current (DC) into the medium meanwhile measuring the electrical potential established in response. The normal resistivity, $R_{a}$ (ohm.m) is evaluated as

$$
R_{a}=\frac{U}{I} \underline{A M}
$$




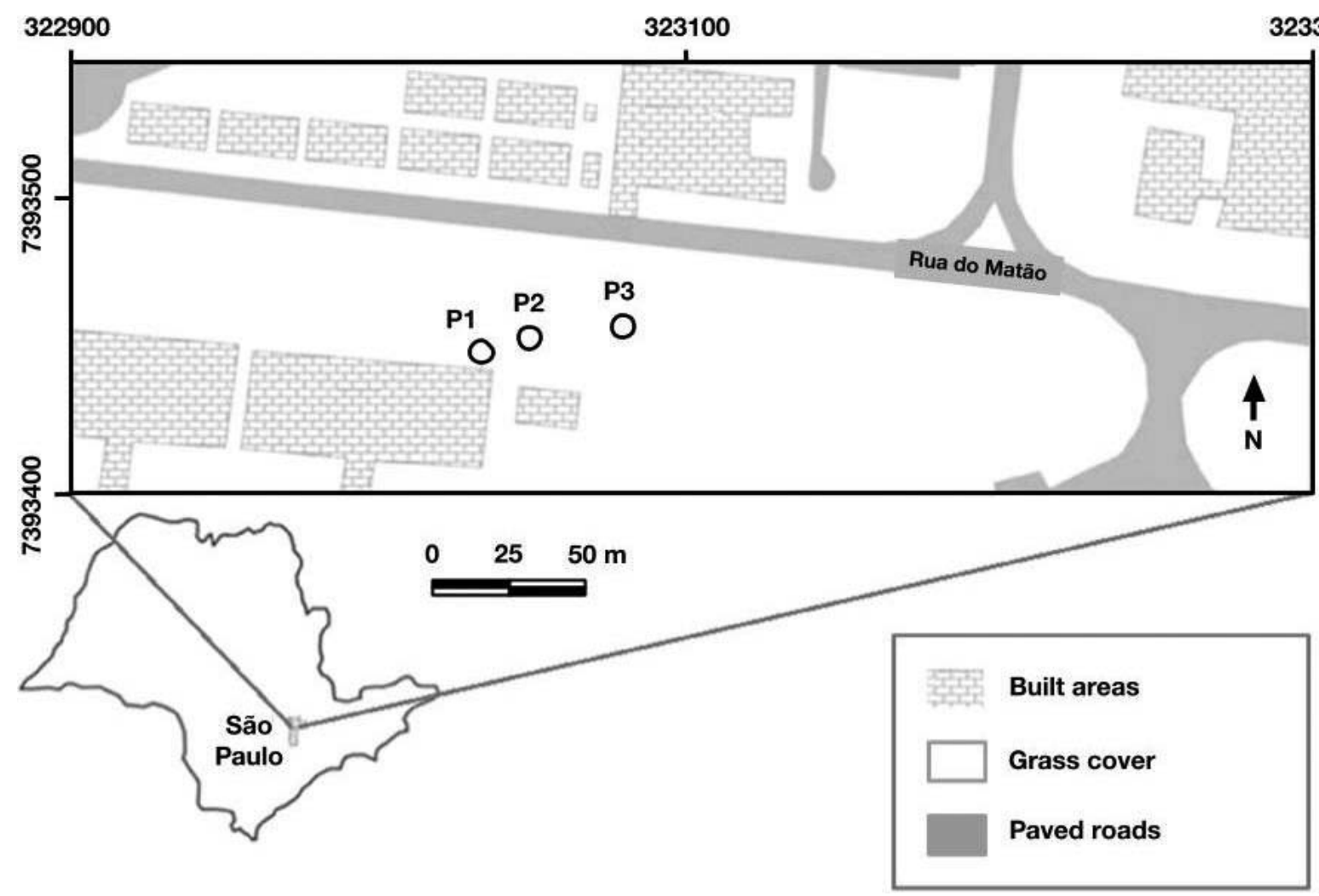

Figure 3 Test site showing a set of three boreholes P1, P2 and P3. Geophysical logs were performed in borehole P2 while slug tests were carried out in all three boreholes. Distance between P2 - P1 and P2 - P3 are $10 \mathrm{~m}$ and $30 \mathrm{~m}$, respectively (Adapted from Porsani et al., 2004).

where $I$ is the electrical current $(A)$ applied at an electrode $A$ mounted at the probe and $U$ the potential difference $(V)$ between a potential electrode $M$ also mounted at the probe with respect to a reference electrode at the ground surface. The distance $\underline{A M}$ accounts for the separation (m) between electrodes $A$ and $M$ at the probe. Common resistivity probes carry multiple electrodes allowing dual $\underline{A M}$ values equal to 64 and 16 inches, for simultaneous measurements of "normal resistivity" N64 and N16, respectively. A deeper volume of investigation (distance with respect to the borehole axis) is obtained with the larger N64 array, on the other hand a higher resolution for localized fractures is provided by the short N16 array. The same set of current electrodes is used to evaluate the single point resistance (SPR) logging. As one of the current electrodes is fixed at the ground surface, the variations in SPR (ohms) with depth thus express the variation occurring in medium properties down the well. In fractured media, SPR shows higher sensitivity to subtle resistivity variations due to fractures, joints and contacts if compared with standard normal resistivity outputs (Keys, 1990). The resistance values in the SPR profile are conditioned by probe specifications (e.g., electrode size) or borehole conditions (e.g., water conductivity) not allowing a quantitative characterization in terms of resistivity properties for the intercepted formations.

Information regarding hydraulic parameters in fractured media can be collected with pumping and injection tests while monitoring water head variations in the tested well and/or a set of nearby wells. Cross borehole pumping can be employed to monitor interference between boreholes and evaluate critical lengths for connected fractures (Paillet, 2013). Water level variations, may however, show interfering effects from changes in the atmospheric pressure (Furbish, 1991), tidal fluctuations (Rojstaczer and Riley, 1990), and long-term hydrological variations (Mukherjee et al., 2017), in some cases compromising data interpretation to determine fracture connectivity.

\section{Percolation Threshold Determination}

A field test was conducted at CSSG - Controlled Site for Shallow Geophysics, of IAG-USP (Porsani et al., 2004), where three boreholes (P1, P2 and P3) with diameters of 4 inches were drilled to $80 \mathrm{~m}$ depth (Fig. 3 ). From the surface and down to $50-55 \mathrm{~m}$ deep in all boreholes the local geology is composed by sedimentary clayey and sandstone layers of the Cenozoic São Paulo Basin. Below the sedimentary pack there is a transition zone with fractured and partially weathered 
Table 1 Fractures identified by OPTV imaging in borehole P2 with respective azimuths and apertures. Apertures not able to be assessed by visual interpretation were set as zero. Only 4 out of 32 fractures showed apertures larger than one centimeter.

\begin{tabular}{|c|c|c|c|c|c|}
\hline Depth (m) & Azimuth and dip & Aperture (cm) & Depth (m) & Azimuth and dip & Aperture (cm) \\
\hline 54.006 & $\mathrm{~N} 016,25.4^{\circ}$ & 0 & 62.687 & $\mathrm{~N} 028,11.5^{\circ}$ & 0 \\
\hline 54.605 & $\mathrm{~N} 358,23.3^{\circ}$ & 0 & 62.690 & $\mathrm{~N} 025,11.1^{\circ}$ & 0.29 \\
\hline 54.619 & $\mathrm{~N} 003,36.1^{\circ}$ & 1.26 & 63.523 & $\mathrm{~N} 354,21.8^{\circ}$ & 0 \\
\hline 54.799 & $\mathrm{~N} 012,22.5^{\circ}$ & 0 & 64.889 & $\mathrm{~N} 000,13.7^{\circ}$ & 0 \\
\hline 56.224 & $\mathrm{~N} 343,8.9^{\circ}$ & 0 & 64.903 & $\mathrm{~N} 012,18.7^{\circ}$ & 1.35 \\
\hline 56.246 & $\mathrm{~N} 018,14.1^{\circ}$ & 2.21 & 70.425 & $\mathrm{~N} 004,23.8^{\circ}$ & 0 \\
\hline 57.879 & $\mathrm{~N} 076,83.8^{\circ}$ & 0 & 70.426 & $\mathrm{~N} 003,24.0^{\circ}$ & 0.11 \\
\hline 58.268 & $\mathrm{~N} 355,31.3^{\circ}$ & 0 & 71.196 & $\mathrm{~N} 270,30.9^{\circ}$ & 0 \\
\hline 58.984 & $\mathrm{~N} 339,34.0^{\circ}$ & 0 & 71.272 & $\mathrm{~N} 313,16.9^{\circ}$ & 0 \\
\hline 59.268 & $\mathrm{~N} 354,31.5^{\circ}$ & 0 & 74.245 & $\mathrm{~N} 082,10.2^{\circ}$ & 0 \\
\hline 60.121 & $\mathrm{~N} 016,15.3^{\circ}$ & 0 & 74.248 & N081, $10.8^{\circ}$ & 0.30 \\
\hline 60.133 & $\mathrm{~N} 009,19.5^{\circ}$ & 1.18 & 74.309 & $\mathrm{~N} 175,77.4^{\circ}$ & 0 \\
\hline 61.502 & $\mathrm{~N} 026,8.8^{\circ}$ & 0 & 74.393 & $\mathrm{~N} 073,77.1^{\circ}$ & 0 \\
\hline 62.240 & $\mathrm{~N} 345,11.3^{\circ}$ & 0 & 74.393 & $\mathrm{~N} 069,77.3^{\circ}$ & 0 \\
\hline 62.676 & $\mathrm{~N} 355,16.1^{\circ}$ & 0.10 & 75.524 & $\mathrm{~N} 284,37.5^{\circ}$ & 0 \\
\hline 62.677 & $\mathrm{~N} 009,19.7^{\circ}$ & 0 & 75.527 & $\mathrm{~N} 282,37.5^{\circ}$ & 0.21 \\
\hline
\end{tabular}

gneissic rocks, gradually grading to hard fresh rocks with depth. The boreholes are cased along the sedimentary section and left uncased (open well) at the resistant hard rock in the deeper sections. For this study, the fracture analysis was only along the uncased interval of well P2.

Well logging studies were developed in borehole P2, situated between wells P1 and P3. As shown in Table 1, a set of 32 fractures were identified from OPTV imaging of the $20 \mathrm{~m}$ open section of borehole P2 with apparent apertures varying from undistin- guishable up to a few centimeters. A full image for P2 borehole is presented in Kowalski et al. (2021).

Among all 32 identified fractures in borehole P2, only four of them $(\sim 12 \%)$ have apertures over one centimeter, suggesting that such isolated open fractures could be the most contributing zones for water circulation. The SPR, N64 and N16 normal resistivity logs of borehole P2 are presented in Fig. 4, along with the depth of fractures with wider apertures identified in the OPTV log.

As in Fig. 4, the resistivity of the gneissic basement (open borehole interval from 55 to 75 meters) shows a

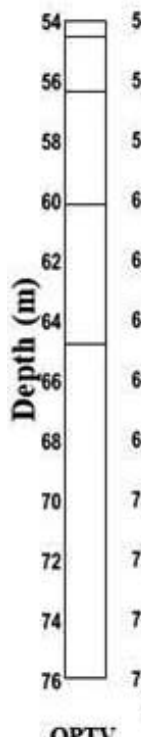

b

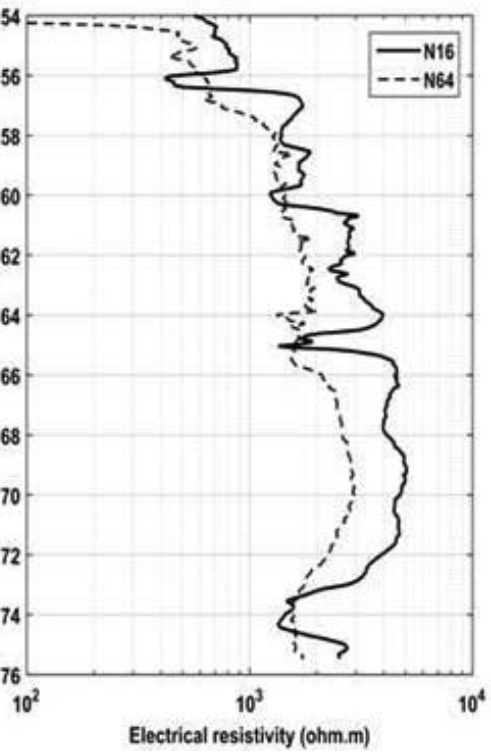

C

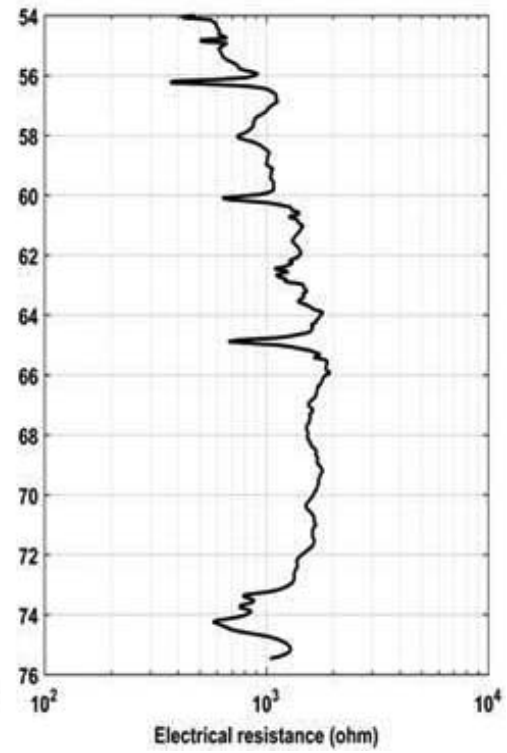

Figure 4 Well logging results for borehole P2: (a) fractures with centimeter-scale apertures, at depths 54, 56, 60 and 65 meters, identified from OPTV imaging of the borehole wall; (b) long (dashed line) and short (solid line) normal resistivity measurements; and (c) single-point resistance log (Adapted from Kowalski, 2017). 
increasing values with depth, distinguished by a staircase-like response limited by sharper variations at depths with open fractures. This behavior is clearly observed in SPR and N16 resistivity, both loggings providing higher resolution of fractures and contacts. Such variations can be related to fractures with centimeter wide apertures at the depths of 54.6, $56.2,60.1$ and $65.0 \mathrm{~m}$. In summary, all fractures in Table 1 with wider apertures show association with sharper resistivity and resistance variations. An exception is the N16 and SPR variations centered at the depth of $74 \mathrm{~m}$ in P2, which is associated with an enriched vein with potassic feldspar, usually more susceptible to jointing and weathering, thus lowering the values in the resistivity and resistance profiles.

According to Equation 3, the percolation threshold can be estimated accounting that 32 fractures were recognized in the open borehole interval with length $z_{w}=22.5 \mathrm{~m}$. This gives a linear density $\lambda_{L}$ of 1.42 fractures per meter and, according to equation 4 a critical length $l_{c}=5.6 / 1.42=3.9 \mathrm{~m}$. This critical length can be interpreted in different ways, either by considering it as a characteristic length that a connected flowline can travel continuously across the medium or, according to approximation $l_{c} \approx \mu_{L}$ that the mean value for the fracture length distribution is equal to $3.9 \mathrm{~m}$. In both interpretations, such a short range of influence would indicate that a well completed into massive hard rock would lack any longer range connectivity to nearby wells, such as P1 and $\mathrm{P} 3$ at the test site, with lateral distances of $10 \mathrm{~m}$ and $20 \mathrm{~m}$, respectively.

\section{Comparison of Percolation Threshold and Cross Borehole Slug Test Results}

Cross borehole slug tests (Audoin and Bodin, 2008) were carried out intending to verify the connectivity of well P2 with nearby wells P1 and P3 (Fig. 5). For this purpose, a mechanical slug causing a displacement of $80 \mathrm{~cm}$ was inserted into one borehole while the water level was monitored in all three boreholes using Solinst ${ }^{\circledR}$ Levelogger Junior (F30, M10) pressure transducers with readings every one second. After a period of about three hours and thirty minutes the slug was removed from the borehole and the water levels were monitored for another long period. This procedure was repeated for all three boreholes.

As shown in Fig. 5, no water head variations appear as a result of the induced pressure gradient generated by insertion/removal of the slug in all three boreholes, indicating there is no connectivity between them. This result corroborates the estimation of a short critical range spanned by the fractures intercepted by borehole P2. Also, from slug test data obtained in all three boreholes, it was possible to
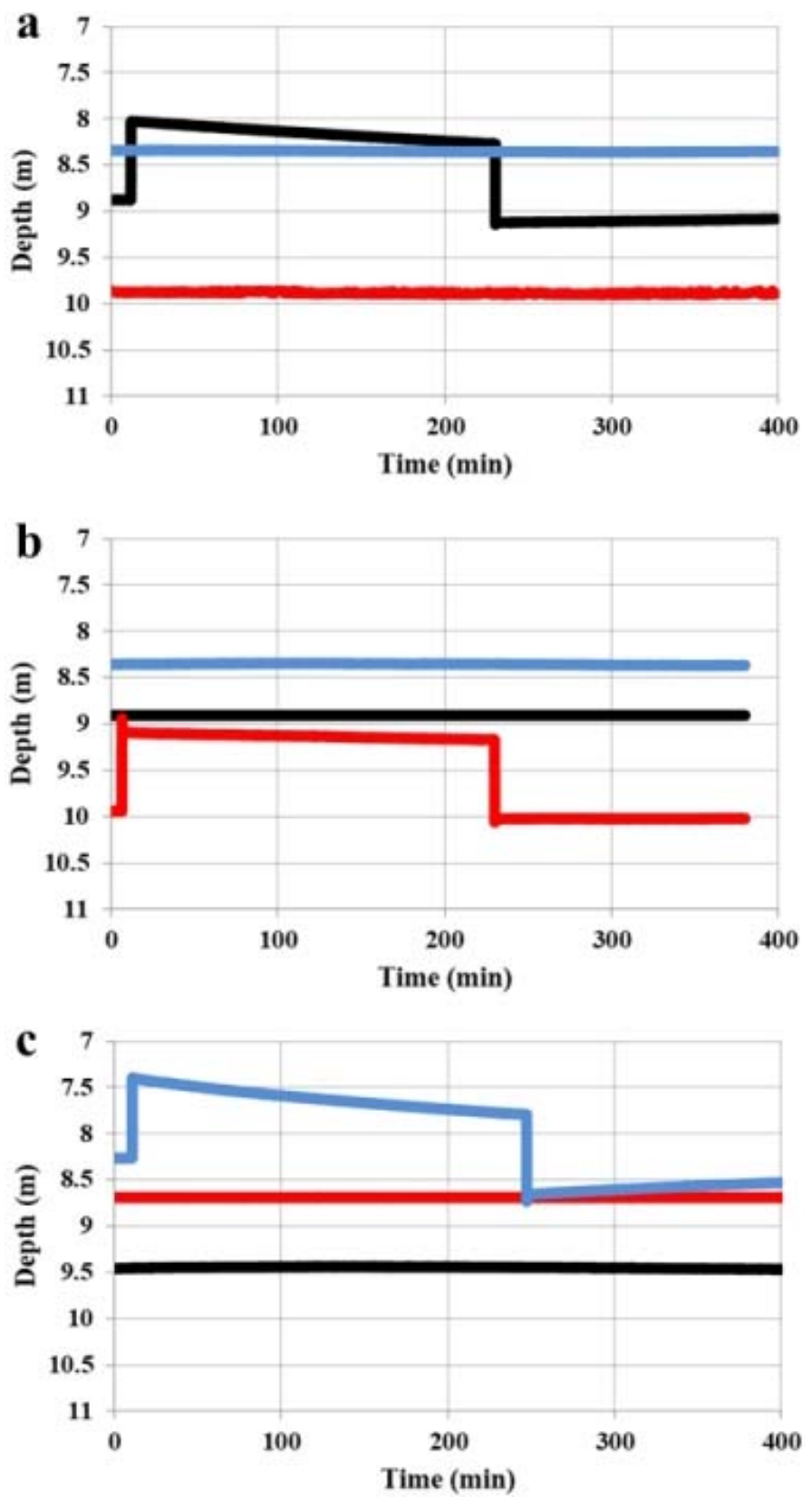

Figure 5 Cross borehole slug tests (a), (b), and (c), conducted at boreholes P1 (black line), P2 (red line) and P3 (blue line), respectively. Water level measurements were taken using automatic pressure transducers with readings every one second. These tests indicate no connection between all three boreholes when the slug is inserted or removed.

evaluate their transmissivities using the Bower and Rice (1976) solution which account for an homogeneous and isotropic aquifer and quasi-steady state flow by neglecting aquifer storativity. Using software AQTESOLV ${ }^{\circledR}$ transmissivities $\left(\mathrm{m}^{2} / \mathrm{s}\right)$ of $1.6 \times 10 \mathrm{E}-7$, $5.4 \times 10 \mathrm{E}-8$, and $3.3 \times 10 \mathrm{E}-7$, were found for boreholes P1, P2 and P3, respectively, which is also in agreement with the low connectivity expected between the boreholes. 


\section{CONCLUSIONS}

This study illustrates how imaging logs can be used to evaluate the critical percolation parameter in boreholes within crystalline rocks which showed consistency with the response of cross borehole slug tests in nearby boreholes, fracture properties observed in electrical well-logging and apparent apertures obtained from optical imaging. The percolation parameter can be evaluated from computing the linear fracture density observed along the well, as recorded by the OPTV imaging of the borehole wall. For the tested well a percolation threshold of $3.9 \mathrm{~m}$ was found, which indicated low fracture connectivity which was observed when analyzing cross borehole slug tests results. As computed from OPTV imaging, most of the observed fractures are tightly closed with only a few of them (4 out of 32) showing apparent apertures greater than $1 \mathrm{~cm}$. The steadily increasing resistivity with depth is consistent with massive, poorly fractured hard rock gneiss, as such bearing fractures with limited extension. Also, the slug tests provided estimates of each borehole transmissivity, with values of $1.6 \times 10 \mathrm{E}-7 \mathrm{~m}^{2} / \mathrm{s}, 5.4 \times 10 \mathrm{E}-8 \mathrm{~m}^{2} / \mathrm{s}$, and $3.3 \times 10 \mathrm{E}-7 \mathrm{~m}^{2} / \mathrm{s}$, for boreholes P1, P2 and P3, respectively, indicative of low connectivity boreholes. Despite the simplicity, where this statistical model assumes a random fracture distribution and properties of fractured rock with isotropic patterns, we conclude that the percolation threshold it provides is consistent with available data. More important is that such relevant parameter conditioning hydraulic transmissivities can easily be obtained from standard welllogging data, which may find applications in many site characterization problems to evaluate groundwater resources or in support to geotechnical investigations.

For our case, under the assumptions made, a fracture length of at least $3.9 \mathrm{~m}$ is necessary to establish a macroscopic hydraulically permeable fracture network. This initially unknown parameter is substantial for the construction of $2 \mathrm{D}$ stochastic networks and simulation of hydraulic flow. With this lower limit, the number of plausible 2D stochastic networks can be restricted.

\section{References}

Audouin 0., and Jacques, B., 2008, Cross-borehole slug test analysis in a fractured limestone aquifer: Journal of Hydrology, 348, 510-523.

Balberg, I., Berkowitz, B., and Drachsler, G.E., 1991, Application of a percolation model to flow in fractured hard rocks: Journal of Geophysical Research, 96(B6) 1001510021.

Barbosa, M.B., Terry, N., Day-Lewis, F.D., Bertolo, R., and Lane, J.W, Jr., 2020, A new R program for flow-log analysis of single holes (FLASH-R): Groundwater, 58, 987992.

Berkowitz, B., 1995, Analysis of fracture network connectivity using percolation theory: Mathematical Geology, 27(4) 467-483.
Berkowitz, B., 2002, Characterizing flow and transport in fractured geological media: A review: Advances in Water Resources, 25, 861-884.

Boisson, A., Guihéneuf, N., Perrin, J., Bour, O., Dewandel, B., Dausse, A., Viossanges, M., Ahmed, S., and Maréchal, J.C., 2015, Determining the vertical evolution of hydrodynamic parameters in weathered and fractured south Indian crystallinerock aquifers: Insights from a study on an instrumented site: Hydrogeology Journal, 23(4) 757-773.

Bour, 0., and Davy, P., 1997, Connectivity of random fault networks following a power law fault length distribution: Water Resources Research, 33(7) 1567-1583.

Boutt, D.F., Diggins, P., and Mabee, S., 2010, A field study (Massachusetts, USA) of the factors controlling the depth of groundwater flow systems in crystalline fracturedrock terrain: Hydrogeology Journal, 18(8) 1839-1854.

Bouwer, H., and Rice, R.C., 1976, A slug test for determining hydraulic conductivity of unconfined aquifers with completely or partially penetrating wells: Water Resources Research, 12(3) 423-428.

Broadbent, S.R., and Hammersley, J.M., 1957, Percolation processes: I. Crystal and mazes: Mathematical Proceedings of the Cambridge Philosophical Society, 53(3) 629-641.

Bunde, A., and Kantelhardt, J.W., 2005, Diffusion and conduction in percolation, in Diffusion in Condensed Matter, Heitjans, P., and Kärger, J. (eds.), Springer, Berlin, Heidelberg, 1-19.

Collins, S.L., and Bianchi, M., 2020, DISOLV: A Python package for the interpretation of borehole dilution tests: Groundwater, 58(5) 805-812.

Day-Lewis, F.D., Johnson, D.C., Paillet, F.L., and Halford, K.J., 2011, A computer program for flow-log analysis of single holes (FLASH): Groundwater, 49(6) 926-931.

Furbish, D.J., 1991, The response of water level in a well to a time series of atmospheric loading under confined conditions: Water Resources Research, 27(4) 557-568.

Gueguen, Y., and Dienes, J., 1989, Transport properties of rocks from statistics and percolation: Mathematical Geology, 21(1) 1-13.

Hamm, S.-Y., Kim, M., Cheong, J.-Y., Kim, J.-Y., Son, M., and Kim, T.-W., 2007, Relationship between hydraulic conductivity and fracture properties estimated from packer tests and borehole data in a fractured granite: Engineering Geology, 92(1-2) 73-87.

Karasaki, K., Freifeld, B., Cohen, A., Grossenbacher, K., Cook, P., and Vasco, D., 2000, A multidisciplinary fractured rock characterization study at Raymond field site, Raymond, CA: Journal of Hydrology, 236, 17-34.

Keys, W.S., 1990, Borehole Geophysics Applied to Ground-Water Investigations: Techniques of Water-Resources Investigations, 2(E2): United States Geological Survey, Denver, Colorado, $150 \mathrm{pp}$.

Kowalski, A.C.G., 2017, Análise da conectividade de fraturas em maciços cristalinos utilizando perfilagem geofísica e modelos de percolação: M. Sc. thesis, University of São Paulo, Instituto de Astronomia, Geofísica e Ciências Atmosféricas, São Paulo, $97 \mathrm{pp}$

Kowalski, A.C.G., Mendonça, C.A., and Ofterdinger, U.S., 2021, Fracture flow characterization with low-noise spontaneous potential logging: Groundwater, 59(1) $16-23$

Mukherjee, A., Gupta, A., Ray, R.K., and Tewari, D., 2017, Aquifer response to rechargedischarge phenomenon: Inference from well hydrographs for genetic classification: Applied Water Science, 7, 801-812.

Ozkaya, S.I., and Mattner, J., 2003, Fracture connectivity from fracture intersections in borehole image logs: Computer e Geosciences, 29(2) 143-153.

Paillet, F., 2013, Cross-borehole flow profiling-delineating subsurface flow paths within a geophysically defined aquifer framework: The Leading Edge, Special edition Hydrogeophysics, 32(7), 758-765.

Porsani, J.L., Borges, W.R., Elis, V.R., Diogo, L.A., Hiodo, F.Y., Marrano, A., and Birelli, C.A., 2004, Investigações geofísicas de superfície e de poço no sítio controlado de geofísica rasa do IAG-USP: Revista Brasileira de Geofísica, 22(3) 245-258.

Rojstaczer, S., and Riley, F.S., 1990, Response of the water level in a well to earth tides and atmospheric loading under unconfined conditions: Water Resources Research, 26(8) 1803-1817.

Shapiro, A., 2001, Characterizing Ground-Water Chemistry and Hydraulic Properties of Fractured-Rock Aquifers Using the Multifunction Bedrock-Aquifer Transportable Testing Tool $\left(\right.$ BAT $^{3}$ ): United States Geological Survey Fact Sheet FS-075-01, 4 pp.

Stauffer, D., and Aharony, A., 1992, Introduction to Percolation Theory, 2nd ed.: Taylor and Francis, London, $192 \mathrm{pp}$.

Stumm, F., Chu, A., Joesten, P.K., and Lane, J.W., 2007, Geohydrologic assessment of fractured crystalline bedrock on the southern part of Manhattan, New York, 
through the use of advanced borehole geophysical methods: Journal of Geophysics and Engineering, 4(3) 245-252.

Vitale, S.A, Robbins, G.A., and Romanowicz, E., 2019, Identifying cross-well fracture connections using the dissolved oxygen alteration method: Journal of Hydrology, 572, 781-789.

Williams, J.H., and Paillet, F.L., 2002, Using flowmeter pulse tests to define hydraulic connections in the subsurface: A fractured shale example: Journal of Hydrology, 265(1-4) 100-117.
Williams, J., and Johnson, C., 2004, Acoustic and optical borehole-wall imaging for fractured-rock aquifer studies: Journal of Applied Geophysics, 55, 151-159.

Zimmermann, G., Burkhardt, H., and Engelhard, L., 2005, Scale dependence of hydraulic and structural parameters in fractured rocks, from borehole data (KTB and HSDP): in Petrophysical Properties of Crystalline Rocks, Harvey, P.K., Brewer, T.S., Pezard, P.A., and Petrov, V.A. (eds.), Geological of Society of London, Special Publications, 240(1), 37-45.

\section{Acknowledgments}

This study was financed in part by the Coordenação de Aperfeiçoamento de Pessoal de Nivel Superior-Brasil (CAPES)—Finance Code 001, Conselho Nacional de Desenvolvimento Científico e Tecnológico (CNPq), FAPESP Project 2017/50241-5, 2018/22533-4 and 2019/23853-5. 


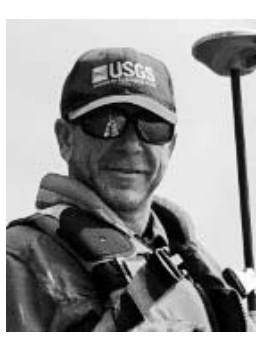

Scott Ikard is a licensed Professional Engineer and Geologist. He is currently a hydrologist in the Geophysics and Subsurface Analysis unit of the United States Geological Survey's Oklahoma-Texas Water Science Center in Austin, Texas. He holds a Ph.D. in Geophysical Engineering from the Colorado School of Mines, an M.E. in Geological Engineering from the Colorado School of Mines, and a B.S. in Geology from James Madison University. Scott serves as Project Chief on applied research studies in geophysics and hydrogeology.

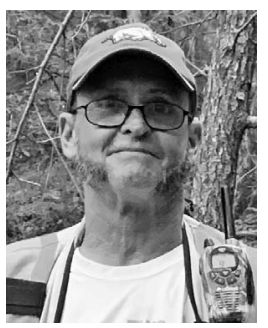

Ferrell Killion is a Hydrographer that serves as a Geospatial Data Collection Specialist in the "Surface Water, Hydraulics and Hydrology Group" within the Lower Mississippi Gulf Water Science Center. He holds M.S. in Geochemistry from Stephen F. Austin State University, Nacogdoches, TX, and a B.S. in Geology from Stephen F. Austin State University. He specializes in "Level's and Datum" and Hydrologic Modeling of Extreme Events and supports investigations into surface water project work.

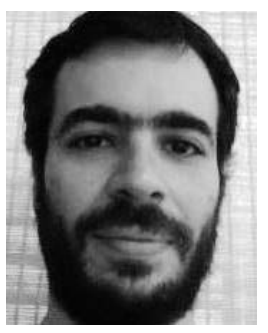

André Kowalski received his M.Sc. degree in Geophysics (2017) and is currently finishing his Ph.D. in Applied Geophysics at the University of São Paulo (Brazil), focusing on well logging for groundwater studies, especially in applications of electrical logs for characterization of fractured zones in crystalline rocks.

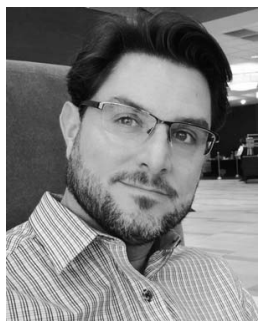

Wade Kress has been a hydrologist for the U.S. Geological Survey since 1996. He has a B.S. in geology from Louisiana Tech University and an M.Sc. in petroleum geosciences from the Petroleum Institute of Abu Dhabi. Wade serves as the Associate Director for the Lower Mississippi-Gulf Water Science Center overseeing the Hydrologic Decision Science Branch. He specializes in geophysical investigations to support hydrogeologic frameworks, contaminant transport, and infrastructure.

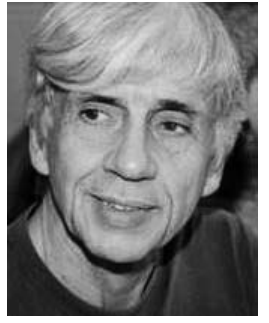

Carlos Mendonça is an Associate Professor at the Department of Geophysics of the University of São Paulo, Brazil. His areas of interest include applying geoelectrical methods in groundwater and near surface studies, interpreting aeromagnetic data for geological and groundwater investigations, and integrating surface and borehole data in nearsurface studies. His current research activities are related to applying borehole data to determine hydrological parameters in crystalline terrains and evaluating hydrological parameters in catchment studies. He is a member of SEG and SBGf (Brazilian Geophysical Society) and a researcher of the Brazilian Research Council (CNPq).

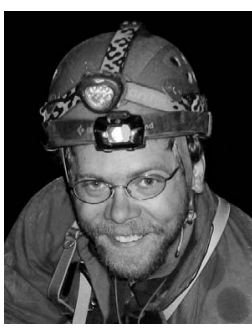

Benjamin Miller is a karst hydrologist working with the Lower Mississippi-Gulf Water Science Center. He holds an M.S. in Hydrology and Geomorphology from Western Kentucky University and a B.S. from the University of MissouriColumbia. His studies focus on hydrologic monitoring of cave and karst systems, delineations of karst recharge areas, spring studies, and biological inventories of cave systems.

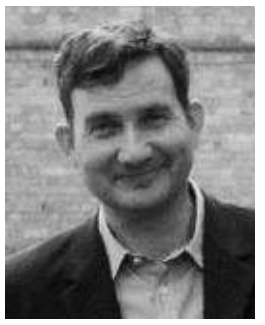

Ulrich Ofterdinger is an Associate Professor at the School of Natural and Built Environment at Queen's University Belfast. A qualified Hydrogeologist (Dr.sc. ETH Zurich) with a first degree in Applied Geology, his main areas of expertise include bedrock hydrogeology, hydrogeophysics, isotope hydrology, aquifer thermal energy storage (ATES) systems, and numerical modeling.

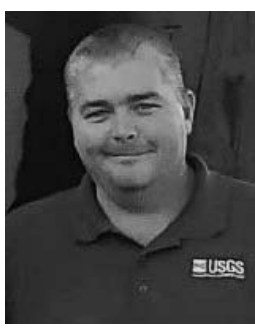

Jason Payne is a geophysicist working with the Geophysics and Subsurface Analysis unit of the United States Geological Survey's Oklahoma-Texas Water Science Center in San Angelo, Texas. He has a B.S. in applied physics from Angelo State University. 